\title{
Weight Loss Trajectories in Bariatric Surgery Patients and
}

\section{Psychopathological Correlates}

Amador García-Ruiz-de-Gordejuela ${ }^{1^{*}}$; Zaida Agüera ${ }^{2,3^{*}}$; Roser Granero ${ }^{2,4}$; Trevor

Steward $^{2,3}$; Asunción Llerda-Barberá ${ }^{4}$; Elena López-Segura ${ }^{4}$; Nuria Vilarrasa ${ }^{5,6}$; Isabel Sanchez $^{3}$; Susana Jiménez-Murcia ${ }^{2,3,7}$; Nuria Virgili ${ }^{5,6}$, Rafael López-Urdiales ${ }^{5}$; Mónica Montserrat-Gil de Bernabe $^{8}$; Pilar Garrido ${ }^{8}$; Rosa Monseny ${ }^{8}$; Carmen Monasterio ${ }^{9,10}$; Neus Salord ${ }^{9,10}$; Jordi Pujol-Gebelli ${ }^{1}$; Jose M Menchón ${ }^{3,7,11}$; Fernando FernándezAranda ${ }^{2,3,7}$

${ }^{I}$ Bariatric and Metabolic Surgery Unit, Service of General and Gastrointestinal Surgery, University Hospital of Bellvitge-IDIBELL, Barcelona, Spain

${ }^{2}$ CIBER Fisiopatologia Obesidad y Nutrición (CIBERobn), Instituto de Salud Carlos III, Barcelona, Spain.

${ }^{3}$ Department of Psychiatry, University Hospital of Bellvitge-IDIBELL, Barcelona, Spain

${ }^{4}$ Department of Psychobiology and Methodology, Autonomous University of Barcelona, Spain

${ }^{5}$ Department of Endocrinology and Nutrition, University Hospital of Bellvitge-IDIBELL, Barcelona, Spain

${ }^{6}$ CIBERDEM-CIBER de Diabetes y Enfermedades Metabólicas Asociadas, Instituto de Salud Carlos III, Madrid, Spain.

${ }^{7}$ Clinical Sciences Department, School of Medicine, University of Barcelona, Spain

${ }^{8}$ Dietetics and Nutrition Unit, University Hospital of Bellvitge, Barcelona, Spain

${ }^{9}$ Pneumology Department, University Hospital of Bellvitge, Barcelona, Spain

${ }^{10}$ CIBER Enfermedades Respiratorias (CibeRes) (CB06/06), Spain

${ }^{11}$ CIBER de Salud Mental (CIBERSAM), Instituto de Salud Carlos III, Barcelona, Spain.

*shared first authorship

Corresponding authors:

This is the author manuscript accepted for publication and has undergone full peer review but has not been through the copyediting, typesetting, pagination and proofreading process, which may lead to differences between this version and the Version of Record. Please cite this article as doi: $10.1002 /$ erv.2558

This article is protected by copyright. All rights reserved. 
Amador García-Ruiz-de-Gordejuela, MD, Bariatric and Metabolic Surgery Unit, General Surgery Department, University Hospital of Bellvitge, c/ Feixa Llarga s/n, 08907 Barcelona, Spain. Tel: +34 93260761; Fax: +34 932607528.

Email: gordeju@icloud.com

Fernando Fernández-Aranda, Ph.D., FAED, Department of Psychiatry, University Hospital of Bellvitge, c/ Feixa Llarga s/n, 08907-Barcelona, Spain (e-mail: fendo@wanadoo.es; Tel. +34 932607227; fax. +34 932607193).

This article is protected by copyright. All rights reserved. 


\begin{abstract}
This study aimed to explore the empirical trajectories of body mass index (BMI) oneyear following bariatric surgery (BS), and to identify the risk factors for each trajectory. The study included 115 patients with severe obesity who underwent BS. Assessment included metabolic variables, psychopathological and personality measures. Growthmixture-modeling identified four separated trajectories for the percentage of total weight loss course-shape (namely T1 "good-fast"; T2 "good "; T3 "low"; and T4 "lowslow"). After adjusting for BS subtype and metabolic baseline state, T1 and T2 registered less eating and general psychopathology. T1 was characterized by the lowest scores in novelty seeking and self-transcendence, whereas T4 was defined by the highest scores in novelty seeking and the in lowest persistence. Our findings suggest that psychological state prior to BS is predictive of BMI trajectories during the 12 months following BS. These results could be useful in developing more efficient interventions for these patients.
\end{abstract}

Keywords: Bariatric surgery, Developmental trajectories, Obesity, Personality, Psychological predictors.

This article is protected by copyright. All rights reserved. 


\section{Introduction}

According to the most recent data published by the World Health Organization (WHO), the worldwide prevalence of obesity has increased dramatically since 1980 in both adults and children ( $\mathrm{Ng}$ et al., 2014). The etiology of obesity is complex and understood to be brought about by an interaction between the environment, genetic predisposition, and human behavior (Swinburn et al., 2011). The positive imbalance between energy intake and energy expenditure, in particular, is believed to be a major contributors to excess weight (Malik, Willett, \& Hu, 2012). Genetic predisposition to obesity is also a relevant risk factor, and it is now known that single gene mutations are responsible for rare forms of monogenic obesity [leptin (LEP), leptin receptor (LEPR), melanocortin-4 receptor (MC4R), and pro-opiomelanocortin (POMC)] (Andreasen \& Andersen, 2009). Common genetic variants or single-nucleotide polymorphisms (SNP) may also play an important role in the obesity epidemic and the obesity-associated gene (FTO) has been found to be associated with an increased risk of common obesity (Hunt et al., 2008). With regards to psychological risk factors, as of late there has been growing interest in identifying the main contributors to the psychological functioning of individuals with obesity and the best predictors on treatment outcomes (Agüera et al., 2015). Recent reviews highlight the potential influence of self-motivation, self-efficacy, locus of control, health related quality of life, self-esteem, concerns about body image, outcome expectations and personality traits on weight control (Armstrong et al., 2011; Brytek-Matera, 2011; Daniali, Azadbakht, \& Mostafavi, 2013; Jokela et al., 2013; Munro, Bore, Munro, \& Garg, 2011). 
Bariatric surgery (BS) is the only effective long-term treatment available for individuals with morbid obesity (Kolotkin \& Andersen, 2017), and it was also associated with reduced mortality(Bray, Frühbeck, Ryan, \& Wilding, 2016). The main indications for bariatric surgery were determined in 1990 by the NIH (NIH, 1992) and they have not been updated. Those guidelines were based only on body composition measures [mainly body mass index (BMI)] and other present comorbid conditions in the patients, such as presence of dyslipidemia (DLP), type 2 diabetes mellitus (T2DM), arterial hypertension (AHT) and obstructive sleep apnea syndrome (OSA).

Body composition constitutes a key component of individuals' and populations' health status, and is determinant in selecting which patients undergo the procedure. The procedures most utilized to assess body composition for research purposes include densitometry, single-cut imaging of the abdomen using computed tomography, magnetic resonance imaging, or dual-energy X-ray absorptiometry (Smith \& Madden, 2016). However, the high cost of these procedures has lead to the use of single measures, such as the BMI (defined as weight in kilograms divided by height in meters squared $\mathrm{kg} / \mathrm{m}^{2}$ ). BMI is currently the most widely used global index of relative weight because of its low cost and simplicity and is considered as a reliable measure of the nutritional status (Beechy, Galpern, Petrone, \& Das, 2012). Likewise, BMI is one criterion to diagnosis certain eating disorders (in combination with additional psychological conditions and behaviors), as well as for categorizing overweight/obesity.

BS procedures are frequently grouped into three main categories : a) predominantly malabsorptive procedures, which are based on reducing the absorption of 
nutrients in the digestive tract; b) predominantly restrictive procedures, acting to reduce oral intake by limiting gastric volume and producing early satiety; and c) mixed procedures, which apply both malabsorptive and restriction methods (Angrisani et al., 2015; Buchwald \& Oien, 2013). The indications for one technique or another is usually based on a patient's BMI and on a surgeon's experience (e.g. e.g. considering medical comorbidities and some aspects from the patient's medical history, such as hiatal hernia or GE reflux).

Studies assessing the effectiveness of BS suggest that maximum weight loss occurs in the months after the surgery, mainly during the first year following the intervention (Goyal \& Watson, 2016). Still, epidemiological studies and meta-analyses also indicate that short-term and long-term efficacy, and the period of time needed for weight loss differ according to the technique used (Colquitt, Pickett, Loveman, \& Frampton, 2014; Garb, Welch, Zagarins, Kuhn, \& Romanelli, 2009; Maggard et al., 2005; Magouliotis et al., 2017) and the pre-surgery medical state of the patient (Maciejewski et al., 2011). New evidence also points to weight loss during the first month as being a predictor of the success or failure of the procedure (Manning et al., 2015; Mor, Sharp, Portenier, Sudan, \& Torquati, 2012; Obeidat \& Shanti, 2015).

Several studies have identified weight loss trajectories after BS, and have assessed specific techniques of BS examining some eating behaviors or metabolic consequences (Conceição et al., 2017; Gómez-Ambrosi et al., 2017). But no study to date, to our knowledge, has sought to compare these weight loss (or BMI) trajectories and identify their main psychopathological and personality predictors after BS. 
Identifying the risk factors in the trajectories of weight loss could be useful in developing more efficient interventions for these patients. As such, the aims of this study were to identify empirical BMI trajectories during the 12-months following BS, and to explore the main risk factors that distinguish patients in the worst outcome trajectories. Based on the existing literature, we hypothesized distinguishable BMI trajectories would be present in our sample and that worse pre-surgery physical and psychological state would be predictive of worse BMI outcomes (i.e. less weight loss and BMI decreases after BS).

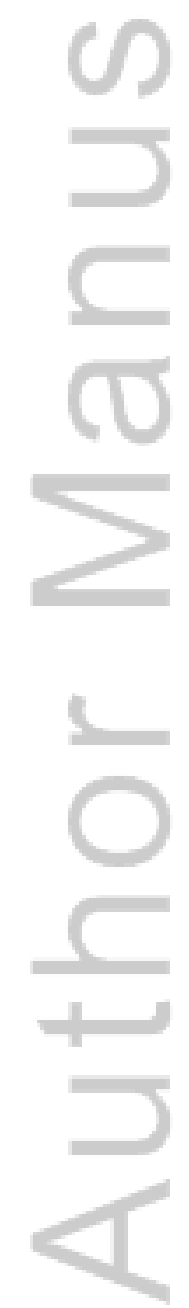

This article is protected by copyright. All rights reserved. 


\section{Materials and Methods}

\section{$\underline{\text { Participants }}$}

The sample included $n=115$ participants with severe obesity [30 males (26.1\%) and 85 females (73.9\%)] who underwent any of four different BS procedures carried out at University Hospital of Bellvitge, Barcelona, Spain (referral and tertiary university hospital): gastric bypass $(n=39,33.9 \%)$, biliopancreatic diversion with duodenal switch $(n=22,19.1 \%)$, vertical sleeve gastrectomy $(n=48,41.7 \%)$, and laparoscopic gastric plication $(n=6,5.2 \%)$. Participant ages ranged from 18 to 62 years-old (mean=41.2, $\mathrm{SD}=10.2)$ and the mean $\mathrm{BMI}$ at recruitment was $46.4 \mathrm{~kg} / \mathrm{m}^{2}(\mathrm{SD}=6.6)$. Most patients were married or lived with a partner $(n=63,54.8 \%)$ and many were also employed $(n=66,57.4 \%)$. From the whole sample, five participants were previously diagnosed with an eating disorder (ED): 2 with binge eating disorder (BED), 2 with bulimia nervosa $(\mathrm{BN})$, and 1 with subthreshold $\mathrm{BN}$. All the individuals with an ED were females.

According to National Institutes of Health (NIH, 1992) guidelines, the inclusion criteria for $\mathrm{BS}$ and, therefore, for the study were: a) $\mathrm{BMI}>40$ or $\mathrm{BMI}>35$ with obesity related comorbidities (DLP, T2DM, AHT and OSA); b) being between the ages of 1865; c) having undergone hypocaloric diet with the guidance of a nutritionist but without expected weight loss; d) a capacity to understand the processes involved in undergoing $\mathrm{BS}$; and e) a desire to complete the surgery procedures. Selection of the BS procedure for each patient was based on the patient's characteristics, specifically age, maximum BMI and other present comorbidities. 


\section{$\underline{\text { Psychological Assessment }}$}

Eating Disorder Inventory-2 (EDI-2; Garner, 1991). This is a reliable and valid multidimensional self-report questionnaire that assesses common cognitive and behavioral characteristics found in eating disorders. The questionnaire consists of 64 items grouped into eleven scales: drive for thinness, body dissatisfaction, maturity fears, bulimia, ineffectiveness, perfectionism, interpersonal distrust, interoceptive awareness, asceticism, impulse regulation, and social insecurity. All questions are answered on a six-point Likert scale and provide standardized subscale scores. The questionnaire is validated in Spanish (Garner, 1998). In the study sample, internal consistency was very good for the total score $(\alpha=0.91)$ and moderate for the primary scales (mean $\alpha=0.69)$.

Symptom Checklist-90 Items-Revised (SCL-90-R; Derogatis, 1990). This 90-item self-report questionnaire is widely used to assess psychopathology through nine primary symptom dimensions (obsessive-compulsive, depression, anxiety, hostility, interpersonal sensitivity, phobic anxiety, somatization, paranoid ideation and psychoticism) and three global indices [the global severity index (GSI), the positive symptom total (PST), and the positive symptom distress index (PSDI)]. The questionnaire is validated in Spanish (Derogatis, 2002). In the study sample internal consistency ranged between $\alpha=0.76$ for paranoid ideation to $\alpha=0.98$ for global index

scales.

Temperament and Character Inventory-Revised (TCI-R; Cloninger, 1990). This 240 -item questionnaire is a reliable and valid measure with 240 items structured in four temperament dimensions (harm avoidance, novelty seeking, reward dependence and 
persistence) and three character scales (self-directedness, cooperativeness and selftranscendence) of personality. We used the Spanish version of the questionnaire (Gutiérrez-Zotes et al., 2004). In the study sample internal consistency ranged between $\alpha=0.73$ for novelty seeking to $\alpha=0.88$ for self-transcendence.

\section{Procedure}

The present study was approved by the Ethics Committee of University Hospital of Bellvitge and all patients provided signed informed consent. Participants were consecutively admitted for assessment prior to surgery at the Department of Psychiatry at the University Hospital of Bellvitge. As a standard procedure of clinical assessment, psychological measures were obtained by experienced psychologists and psychiatrists and a face-to-face interview was conducted in order to screen for the presence of any current or lifetime psychiatric disorders. Psychiatric disorder diagnosis was assessed by means of a clinical and psychopathological semi-structured interview (which includes somatic personal antecedents, eating disorder/abnormal eating, and current or lifetime psychiatric treatment) (Fernández-Aranda \& Turón, 1998), based on the validated SCID-I interview (First, Spitzer, Gibbon, \& Williams, 2002), and conducted by experienced clinical psychologists and psychiatrists. In addition to psychological assessment, further demographic/clinical information was obtained during this assessment. The aforementioned questionnaires were administered individually before BS. Psychological/psychiatric assessment was required for bariatric surgery approval. 
A highly trained team of endocrinology specialists and surgeons at the Department of Endocrinology and at the Bariatric and Metabolic Surgery Unit of University Hospital of Bellvitge obtained anthropometric and nutritional variables before BS.

\section{$\underline{\text { Statistical analyses }}$}

Statistical analyses were carried out with MPlus 8 for Windows. The trajectories were estimated considering the percentage of total weight loss (TWL) during the first year after BS as an indicator. Due to the strong association between this measure and initial weight, estimation was carried out including baseline BMI as a covariate. Growth-mixture-modeling (GMM) was used, defining the robust maximum likelihood (MLR) estimator in the Analysis command (for full information on this method please consult Enders \& Bandalos, 2001 and Graham, 2009) and using Lo-Mendell-Rubin (Lo, Mendell, \& Rubin, 2001) as a measure to determine the number of classes. The selection of the number of trajectories for each of the five measures considered was based on (Nylund, Asparouhov, Muthén, \& Muthén, 2007): a) the lowest Akaike (AIC) and Bayesian information criterion (BIC) indexes for the model (compared with other solutions); b) entropy (measure of the model's discriminative capacity, that is, its ability to identify individuals following the different trajectories) above .80; c) high ondiagonal average values (around .80) in the matrix containing the probabilities of membership (that is, high average latent class probabilities for most likely latent class 
membership by latent class); d) no less than $5 \%$ of participants in a class/trajectory (to allow statistical comparisons); and e) adequate clinical interpretability.

The comparison between the empirical trajectories was carried out with chisquare tests for categorical variables and analysis of variance (ANOVA) for quantitative variables. Clinical comparisons were adjusted for BS subtype and for the presence of metabolic conditions at baseline (Type-2 diabetes mellitus, arterial hypertension, dyslipidemia and OSA). Cohen's- $d$ coefficient measured effect size for pairwise comparisons $(|d|>0.50$ was considered moderate effect size and $|d|>0.80$ was considered good effect size).

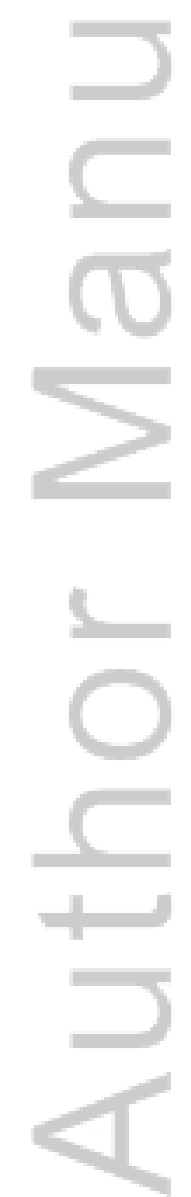

This article is protected by copyright. All rights reserved. 


\section{Results}

\section{Trajectories for TWL}

Table S1 (see supplementary information), shows the goodness-of-fit for the different candidate models obtained in the GMM, with the number of trajectories ranging from two to four. Solution models for more than four trajectories were not considered due to the lack of convergence and/or very small classes.

The final model selected was the four-trajectory solution (whose TWL shapes are represented in the first panel of Figure 1). This model yielded the lowest AIC-BIC indexes $(\mathrm{AIC}=2851.92, \quad \mathrm{BIC}=2945.243$ and adjusted sample-size $\mathrm{BIC}=2837.77)$, excellent entropy (.941), very high on-diagonal values in the matrix with the average latent class probabilities (between .965 and .991), and good clinical interpretability. To facilitate the interpretation of each trajectory, the second panel in Figure 1 shows the BMI courses for each trajectory.

\section{--- Insert Figure 1 ---}

Trajectory $\mathrm{T} 1(n=19,16.5 \%)$ represented patients who achieved the highest TWL at each measure (means between $29.9 \%$ at 3-months after BS to $42.6 \%$ at the 12 month follow-up), and also the highest BMI decreases (means changed from $41.3 \mathrm{~kg} / \mathrm{m}^{2}$ at pre-surgery to $23.4 \mathrm{~kg} / \mathrm{m}^{2}$ at 12 -month follow-up). This trajectory was labeled as "good-fast loss". Three of the five participants previously diagnosed with an ED were in this trajectory (one with $\mathrm{BED}$, one with $\mathrm{BN}$ and one with subthreshold $\mathrm{BN}$ ).

Trajectory T2 (n=46, 40.0\%) included the highest proportion of patients, and showed a good TWL (means increased from $25.1 \%$ at 3-months after BS to $38.5 \%$ at 
12-months follow-up). The BMI means decreased for these patients from $44.9 \mathrm{~kg} / \mathrm{m}^{2}$ at pre-surgery to $27.5 \mathrm{~kg} / \mathrm{m}^{2}$ at 12 -months follow-up. This trajectory was labeled in this study as "good loss".

Trajectory T3 $(n=31,27.0 \%)$ included patients with lower TWL compared to the previously described trajectories, with mean values ranging from $19.9 \%$ to $31.5 \%$ during the follow-up after BS (means for the BMI decreased from $47.1 \mathrm{~kg} / \mathrm{m}^{2}$ prior-BS to $32.1 \mathrm{~kg} / \mathrm{m}^{2}$ at the 12 -month follow-up). This trajectory was labeled as "low loss".

Trajectory T4 $(n=19,16.5 \%)$ included patients with the lowest weight loss in the study (means for TWL were $17.2 \%$ at 3 months post-BS to $27.2 \%$ at 12 -months followup). The BMI means decreased from $54.0 \mathrm{~kg} / \mathrm{m}^{2}$ prior-BS to $39.2 \mathrm{~kg} / \mathrm{m}^{2}$ at $12-\mathrm{months}$ follow-up. This trajectory was labeled as "low-slow loss". Two of the five participants previously diagnosed with an ED were in this trajectory (one with BED, and one with $\mathrm{BN})$.

Polynomial contrasts indicated significant positive linear trends for all the TWL trajectories (first panel in Figure 1). For the BMI courses associated to the empirical trajectories, polynomial contrast indicated both negative linear trends and quadratic linear trends (the highest BMI decreases were achieved during the first trimester after $\mathrm{BS})$.

Differences between trajectories in sociodemographic characteristics

Table 1 shows the frequency distribution for the main sociodemographic variables of the study, and the comparison between the empirical trajectories. No significant difference between trajectories were obtained for the participants' sex 
$\left(\chi^{2}=0.89, d f=3, p=.828\right)$ and age $(\mathrm{F}=1.19, d f=3-111, p=.315)$. Significant differences were found for the civil status and the employment status (T4 "low-slow" registered the lowest proportion of married or "living with a partner" participants and the highest proportion of unemployed individuals).

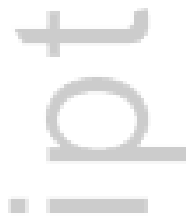

--- Insert Table 1 ---

Differences between trajectories in BS subtype and metabolic state at baseline

Table 2 shows the frequency distribution for BS subtype (real and that should be indicated based on the patients' age and BMI prior to BS, see Table S2 supplementary) and the presence of the main metabolic variables of the study (Type-2 diabetes mellitus, arterial hypertension, dyslipidemia and apnea obstructive syndrome). For the BS types, differences between trajectories emerged between gastric bypass (T4 "low-slow" registered the lowest proportion of patients with this technique) and duodenal switch (T1 "good-fast" and T2 "good" had the lowest proportions compared to T3 "low" and T4 "low-slow"). Differences also emerged considering the indicated BS subtype: T1 "good-fast" and T2 "good" registered the highest proportion of patients with gastric bypass, while T3 "low" and T4 "low-slow" had the highest proportion with duodenal switch. For metabolic state at baseline, T2 "good" and T3 "low" reported the highest prevalence of hypertension, while T1 "good-fast" had significantly lower prevalence of OSA than T3 "low".

--- Insert Table 2 --- 
$\underline{\text { Baseline differences between trajectory groups in psychological variables }}$

Table 3 includes measures of psychopathological state (SCL-90R), eating disorder symptomathology (EDI-2) and personality traits (TCI-R). Results of the comparison between trajectories obtained in ANOVA procedures were adjusted for the BS-type and the metabolic state at baseline (Type-2 diabetes mellitus, arterial hypertension, dyslipidemia and apnea obstructive syndrome prior to BS). As a whole, T1 "good-fast" and T2 "good" were characterized by lower levels of psychopathology and less disorder eating behaviors. No differences in these measures were found comparing these two trajectories. Interestingly, participants in these two trajectories labeled as good TWL courses (T1 and T2) endorsed higher mean scores on the EDI-2 perfectionism scale compared to the T3 course characterized as low TWL. T4 "lowslow" had the highest levels of psychopathology and disorder eating, followed by T3 "low". Considering personality characteristics, T1 "good-fast" and T2 "good" obtained higher means than T3 "low" and T4 "low-slow" in cooperativeness; T1 "good-fast" also included participants with lower scores in novelty seeking than T4 and less self-transcendence than T3. T4 "low-slow" reported less persistence than T1 and T3. T3 "low" reported the highest means for self-transcendence and T4 "low-slow" the highest means in novelty seeking and the lowest means in persistence and cooperativeness.

--- Insert Table 3 --- 
Figure 2 contains a radar-chart to graphically illustrate the main differences between trajectories (z-standardized means have been plotted to allow for easier interpretation due to the different scale ranges).

--- Insert Figure 2 ---

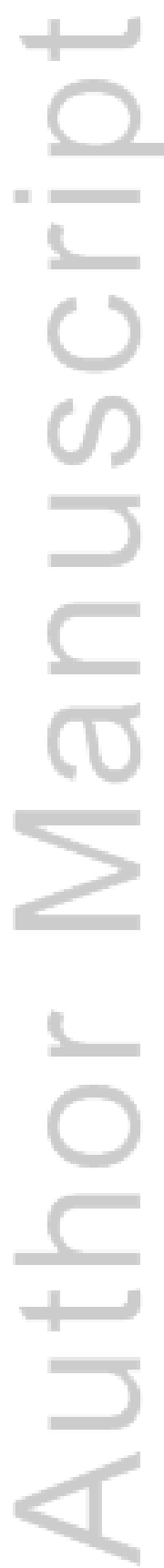

This article is protected by copyright. All rights reserved. 


\section{Discussion}

This study used group-based trajectory modeling to identify the number and shape of TWL trajectories (adjusted for baseline BMI) during the 12 months following BS. The adequate goodness-of-fit of the final model, its clinical interpretability and the good capacity to discriminate psychological constructs (via psychopathological and personality traits) supported the validity of these empirical trajectories.

Four trajectories emerged (namely T1 "good-fast"; T2 "good "; T3 "low"; and T4 "low-slow"), with no significant differences in the patients' sex and age. T1 "goodfast" and T2 "good" tended to score lower levels of eating and general psychopathology (individuals with less eating symptomatology and more functional), and the highest mean scores in the personality scales of perfectionism and cooperativeness (namely individuals described as perseverant despite frustration and with more determination, but also more empathic and tolerant). Although the mean scores of each personality scale were in the normal range for all trajectories (GutiérrezZotes et al., 2004), significant differences between groups were found. Interestingly, T1 "good-fast" was characterized by the lowest levels in novelty seeking and selftranscendence (namely individuals described as less impulsive and more reflective). T3 "low" and T4 "low-slow" trajectories reported the highest levels of psychopathology and lowest scores in the cooperativeness personality scale. Since high levels of cooperativeness (namely individuals described as empathic and tolerant) has been regarded as a sign of psychological maturity (Cloninger, Svrakic, \& Przybeck, 1993), this finding might explain why patients with low levels of cooperativeness are more 
likely to have worse outcomes than those with higher levels. These findings are in line with previous studies that found that lower cooperativeness levels were associated with high BMI in patients with obesity (Hintsanen et al., 2012) whereas, on the contrary, high cooperativeness has been related to successful BS outcome (Agüera et al, 2015). T4 was also characterized by the highest levels in novelty seeking and the lowest levels in persistence. This result is coherent with the evidence reported in the scientific literature suggesting that the worse pre-surgery psychological clinical state is predictive of poorer post-surgery outcomes (Agüera et al., 2015; Gade, Rosenvinge, Hjelmesæth, \& Friborg, 2014; Rotella et al., 2014).

The largest differences in psychological variables were found between T2 "good" and T4 trajectories "low-slow", with patients in the T4 trajectory presenting the highest levels of psychopathology (namely higher scores in hostility and interpersonal distrust, but also in general psychopathology) than those in T2. Moreover, patients in the T4 trajectory showed more eating-related symptomatology than those in T2, mainly higher scores on impulse regulation, maturity fears and bulimia, traits generally associated with emotional eating, binge eating behaviors or binge eating disorder. However, the five patients presenting any type of eating disorder, such as BED or $\mathrm{BN}$ were distributed in the $\mathrm{T} 1$ and $\mathrm{T} 4$ trajectories alike in our sample. Therefore, despite the participants in T4 presenting more eating-related psychopathology, we were not able to find a greater representation of ED cases in the T4 trajectory. These findings are discrepant with previous studies suggesting that the pre-surgical presence of BED impairs weight loss following bariatric surgery (Niego, Kofman, Weiss, \& Geliebter, 
2007), but they seem to be in line with other studies suggesting that pre-surgical BED does not attenuate weight loss (Conceição et al., 2017; Wadden et al., 2011). However, the low sample size of participants with ED does not allow meaningful comparisons. Future studies should analyze larger samples of ED patients following BS to evaluate if the preoperative presence of an ED is a predictor of weight loss trajectories (Conceição, Utzinger, \& Pisetsky, 2015).

Interestingly, T4 seemed to represent an entirely distinct trajectory: a poor BS outcome characterized by a low and slow TWL decrease, along with a psychopathological and eating state that was very similar to T3 (statistically relevant differences between both trajectories only emerged for the EDI-2 bulimia scale, with highest mean for T4). This result seems consistent with evidence indicating a strong association between worse pre-surgery clinical state with worse surgery outcome (Conceição et al., 2015; Legenbauer, Petrak, de Zwaan, \& Herpertz, 2011; Livhits et al., 2012; Odom et al., 2010; Pataky, Carrard, \& Golay, 2011; Wimmelmann, Dela, \& Mortensen, 2014a, 2014b). One potential explanation for this result is the highest mean score in the novelty seeking personality trait and the lowest mean score in persistence trait found in participants in the T4 trajectory, along with the fact that these participants were most likely to be single and unemployed. Novelty seeking has been defined as the tendency to be more impulsive, excitable, dramatic, and intolerant of routine, therefore, it is not surprising that higher scores in novelty seeking are related to more problems in following treatment guidelines and weight-loss recommendations (Hintsanen et al., 2012; Montesi et al., 2016; Sullivan, Cloninger, Przybeck, \& Klein, 2006). This finding 
is also in line with prior research showing that greater impulsivity was associated with greater difficulty with weight loss (Dalle Grave et al., 2015), as well as a higher risk of weight regain following BS at 2-year follow up (Karmali et al., 2013). Likewise, being that the persistence personality trait has been defined as having perseverance despite frustration and fatigue (Cloninger et al., 1993), this finding might explain why patients scoring higher in persistence were more likely to respond better to BS as this characteristic promotes positive changes. From a clinical point of view, although the mean personality scores for all the trajectories were in the normal range (GutiérrezZotes et al., 2004), T4 revealed the lowest scores in persistence. These results suggest that this group may have a lower external locus of control and, therefore, encounter more difficulties in planning challenges and achieving goals. Additional studies are required to assess the underlying mechanism for the BS outcomes, particularly to explore to what extent personality levels at pre-surgery and sociodemographic features mediate between psychological state and body composition trajectories after BS (Peterhänsel, Linde, Wagner, Dietrich, \& Kersting, 2017).

The present study should be evaluated within the context of several limitations. First, the results must be interpreted cautiously, as psychological assessment is a precondition to be eligible for BS, patients might have attempted to present themselves in a better light in order to be approved for surgery. Second, the waitlists for BS in the public healthcare system can reach up to two to three years meaning that our results cannot be generalized as there were a considerable number of patients that dropped out because they may have sought BS treatment in private hospitals. Third, we only 
assessed participants for 12 months following BS and there is no way of knowing yet the extent to which their weight loss may persist over time. Finally, with the aim of allowing for statistical comparisons, this study only considered GMM with no less than $5 \%$ of participants in a class-trajectory as finalists, and this could have conditioned the results since this criterion reduces the finer graded differences between different BMI courses within the BS spectrum. Future research should aim to overcome the aforementioned limitations, expanding the sample size for each BS procedure, and including for a long-term follow-up. Also, it would be of interest to assess in larger samples if pre-existing pathological eating behaviors such as emotional eating or binge eating disorder could potentially be considered as a predictor of weight loss trajectories.

In spite of the abovementioned limitations, the current study also possesses several strengths. This study was designed to expand upon limitations in the current literature by using a comprehensive pre-surgical psychological assessment including socio-demographic features, dysfunctional eating behaviors, psychopathology, and a complete medical evaluation. Furthermore, this research attempted to overcome the limitations of the previous studies by including a large sample of consecutive referred patients with severe obesity in a large range of age that underwent different techniques of BS.

The analytical procedures used in this work also constitute a methodological strength. The study of the heterogeneity among candidate BS patients has mostly been assessed through variable-level approaches (such as regression modeling and general linear models), which are centered on describing the association between variables and 
that consider the potential risk-or-protective factors as predictors of the surgery outcome. This approach tends to isolate clinical meaningful characteristics in which individuals reliably differ, since it is focused on the analysis of their potential correlational structure, stability over time, and predictive validity for patients' outcomes. Therefore, variable-level approaches do not provide information about the person-specific intra-individual clinical state or about the person-specific intraindividual progress. Contrarily, person-centered approaches (such as mixed growth modeling, latent class or cluster analysis) start by grouping individuals according to their own responses/scores, and focus attention on the intra-individual structure of variables, with the advantage of conceiving individuals as a whole and not as the sum of isolated features. Therefore, BS trajectories obtained from these methods should be considered as being well suited for addressing questions that concern group differences in clinical profiles.

Regarding implications of this study, our findings confirm that specific psychopathological and personality traits might influence different weight-loss trajectories after BS. Therefore, these results put forward future lines of research on developmental BMI courses and about the protective/risk factors for each specific trajectory. Moreover, our findings suggest that some strategies could potentially enhance results in these patients. For example, strategies to cope with middle-long term goals and specific personality traits, such as techniques for decreasing impulsivity, or enhancing persistence, self-directedness and cooperativeness could be recommended before BS (Claes \& Müller, 2015; Kalarchian \& Marcus, 2015). In this line, the 
development of a temperament and character-focused treatment would be useful in these patients, in the same way it has been applied in some eating disorders (Kaye et al., 2015).

\section{Acknowledgements}

Funding sources: This manuscript was supported by grants of Instituto de Salud Carlos III (ISCIII) [grant number FIS PI14/00290 and European Regional Development Fund (ERDF/FEDER)-"a way to Build Europe"] and by a grant of the Ministerio de Economía y Competitividad (grant number PSI2015-68701-R). Centro de Investigación Biomédica en Red Fisiopatología de la Obesidad y Nutrición (CIBERobn), CIBER de

Diabetes $=$ y Enfermedades Metabólicas Asociadas (CIBERDEM), CIBER de Enfermedades Respiratorias (CibeRes), and CIBER en Red Salud Mental (CIBERSAM) are initiatives of ISCIII.

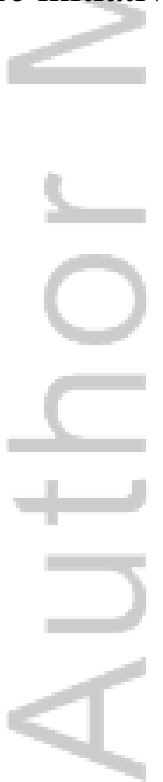

This article is protected by copyright. All rights reserved. 


\section{References}

Agüera, Z., García-Ruiz-de-Gordejuela, A., Vilarrasa, N., Sanchez, I., Baño, M., Camacho, L., ... Menchón, J. M. (2015). Psychological and Personality Predictors of Weight Loss and Comorbid Metabolic Changes After Bariatric Surgery.

European Eating Disorder Review, 23(6), 509-16.

https://doi.org/10.1002/erv.2404

Andreasen, C. H., \& Andersen, G. (2009). Gene-environment interactions and obesity—Further aspects of genomewide association studies. Nutrition, 25(10),

998-1003. https://doi.org/10.1016/j.nut.2009.06.001

Angrisani, L., Santonicola, A., Iovino, P., Formisano, G., Buchwald, H., \& Scopinaro, N. (2015). Bariatric Surgery Worldwide 2013. Obesity Surgery, 25(10), 1822-32. https://doi.org/10.1007/s11695-015-1657-z

Armstrong, M. J., Mottershead, T. A., Ronksley, P. E., Sigal, R. J., Campbell, T. S., \& Hemmelgarn, B. R. (2011). Motivational interviewing to improve weight loss in overweight and/or obese patients: a systematic review and meta-analysis of randomized controlled trials. Obesity Reviews, 12(9), 709-723. https://doi.org/10.1111/j.1467-789X.2011.00892.x

Beechy, L., Galpern, J., Petrone, A., \& Das, S. K. (2012). Assessment tools in obesity psychological measures, diet, activity, and body composition. Physiology \& Behavior, 107(1), 154-71. https://doi.org/10.1016/j.physbeh.2012.04.013

Bray, G. A., Frühbeck, G., Ryan, D. H., \& Wilding, J. P. H. (2016). Management of obesity. The Lancet, 387(10031), 1947-1956. https://doi.org/10.1016/S0140-

This article is protected by copyright. All rights reserved. 
6736(16)00271-3

Brytek-Matera, A. (2011). Exploring the factors related to body image dissatisfaction in the context of obesity. Archives of Psychiatry and Psychotherapy, 1, 63-70.

Buchwald, H., \& Oien, D. M. (2013). Metabolic/bariatric surgery worldwide 2011. Obesity Surgery, 23(4), 427-36. https://doi.org/10.1007/s11695-012-0864-0

Claes, L., \& Müller, A. (2015). Temperament and Personality in Bariatric SurgeryResisting Temptations? European Eating Disorders Review, 23(6), 435-441. https://doi.org/10.1002/erv.2398

Cloninger, C. R. (1999). The Temperament and Character Inventory-Revised. St Louis, MO: Center for Psychobiology of Personality, Washington University.

Cloninger, C. R., Svrakic, D. M., \& Przybeck, T. R. (1993). A psychobiological model of temperament and character. Archives of General Psychiatry, 50(12), 975-990.

Colquitt, J. L., Pickett, K., Loveman, E., \& Frampton, G. K. (2014). Surgery for weight loss in adults. The Cochrane Database of Systematic Reviews, 8, CD003641. https://doi.org/10.1002/14651858.CD003641.pub4

Conceição, E. M., Mitchell, J. E., Pinto-Bastos, A., Arrojado, F., Brandão, I., \& Machado, P. P. P. (2017). Stability of problematic eating behaviors and weight loss trajectories after bariatric surgery: a longitudinal observational study. Surgery for Obesity and Related Diseases, 13(6), 1063-1070. https://doi.org/10.1016/j.soard.2016.12.006

Conceição, E. M., Utzinger, L. M., \& Pisetsky, E. M. (2015). Eating Disorders and Problematic Eating Behaviours Before and After Bariatric Surgery:

This article is protected by copyright. All rights reserved. 
Characterization, Assessment and Association with Treatment Outcomes.

European Eating Disorders Review, 23(6), 417-425.

https://doi.org/10.1002/erv.2397

Dalle Grave, R., Calugi, S., Compare, A., El Ghoch, M., Petroni, M. L., Colombari, S.,

... Marchesini, G. (2015). Personality, attrition and weight loss in treatment seeking women with obesity. Clinical Obesity, 5(5), 266-272.

https://doi.org/10.1111/cob.12112

Daniali, S., Azadbakht, L., \& Mostafavi, F. (2013). Relationship between body satisfaction with self esteemand unhealthy body weight management. Journal of Education and Health Promotion, 2(1), 29. https://doi.org/10.4103/22779531.115804

Derogatis, L. R. (1994). SCL-90-R: Symptom Checklist-90-R. Administration, Scoring and Procedures Manuall—II for the revised version. Towson; MD: Clinical Psychometric Research.

Derogatis, L. R. (2002). SCL-90-R. Cuestionario de 90 síntomas-Manual. Madrid: TEA Editorial.

Enders, C., \& Bandalos, D. (2001). The Relative Performance of Full Information Maximum Likelihood Estimation for Missing Data in Structural Equation Models. Structural Equation Modeling: A Multidisciplinary Journal, 8(3), 430-457. https://doi.org/10.1207/S15328007SEM0803_5

Fernández-Aranda, F., \& Turón, V. (1998). Trastornos alimentarios. Guia basica de tratamiento en anorexia y bulimia. Barcelona: Masson.

This article is protected by copyright. All rights reserved. 
First, M. B., Spitzer, R. L., Gibbon, M., \& Williams, J. B. W. (2002). Structured Clinical Interview for DSM-IV-TR Axis I Disorders, Research Version, Patient Edition. (SCID-I/P). New York: Biometrics Research, New York State Psychiatric Institute.

Gade, H., Rosenvinge, J. H., Hjelmesæth, J., \& Friborg, O. (2014). Psychological correlates to dysfunctional eating patterns among morbidly obese patients accepted for bariatric surgery. Obesity Facts, 7(2), 111-9.

https://doi.org/10.1159/000362257

Garb, J., Welch, G., Zagarins, S., Kuhn, J., \& Romanelli, J. (2009). Bariatric surgery for the treatment of morbid obesity: a meta-analysis of weight loss outcomes for laparoscopic adjustable gastric banding and laparoscopic gastric bypass. Obesity Surgery, 19(10), 1447-1455. https://doi.org/10.1007/s11695-009-9927-2

Garner, D. M. (1991). Eating Disorder Inventory-2. Odessa: Psychological Assessment Resources.

Garner, D. M. (1998). Inventario de Trastornos de la Conducta Alimentaria (EDI-2)Manual. Madrid: TEA.

Gómez-Ambrosi, J., Andrada, P., Valentí, V., Rotellar, F., Silva, C., Catalán, V., ... Frühbeck, G. (2017). Dissociation of body mass index, excess weight loss and body fat percentage trajectories after 3 years of gastric bypass: relationship with metabolic outcomes. International Journal of Obesity. https://doi.org/10.1038/ijo.2017.134

Goyal, D., \& Watson, R. R. (2016). Endoscopic Bariatric Therapies. Current 
Gastroenterology Reports, 18(6), 26. https://doi.org/10.1007/s11894-016-0501-5

Graham, J. W. (2009). Missing Data Analysis: Making It Work in the Real World.

Annual Review of Psychology, 60(1), 549-576.

https://doi.org/10.1146/annurev.psych.58.110405.085530

Gutiérrez-Zotes, J. A., Bayón, C., Montserrat, C., Valero, J., Labad, A., \& Cloninger, C. R. (2004). Temperament and Character Inventory-Revised (TCI-R).

Standardization and normative data in a general population sample. Actas Españolas de Psiquiatria, 32(1), 8-15.

Hintsanen, M., Jokela, M., Cloninger, C. R., Pulkki-Råback, L., Hintsa, T., Elovainio,

M., ... Keltikangas-Järvinen, L. (2012). Temperament and character predict bodymass index: A population-based prospective cohort study. Journal of

Psychosomatic Research, 73(5), 391-397.

https://doi.org/10.1016/j.jpsychores.2012.08.012

Hunt, S. C., Stone, S., Xin, Y., Scherer, C. A., Magness, C. L., Iadonato, S. P., ...

Adams, T. D. (2008). Association of the FTO Gene With BMI. Obesity, 16(4), 902-904. https://doi.org/10.1038/oby.2007.126

Jokela, M., Hintsanen, M., Hakulinen, C., Batty, G. D., Nabi, H., Singh-Manoux, A., \& Kivimäki, M. (2013). Association of personality with the development and persistence of obesity: a meta-analysis based on individual-participant data.

Obesity Reviews

Study of Obesity, 14(4), 315-23. https://doi.org/10.1111/obr.12007

Kalarchian, M. A., \& Marcus, M. D. (2015). Psychosocial Interventions Pre and Post

This article is protected by copyright. All rights reserved. 
Bariatric Surgery. European Eating Disorders Review, 23(6), 457-62.

https://doi.org/10.1002/erv.2392

Karmali, S., Brar, B., Shi, X., Sharma, A. M., de Gara, C., \& Birch, D. W. (2013).

Weight Recidivism Post-Bariatric Surgery: A Systematic Review. Obesity Surgery, 23(11), 1922-1933. https://doi.org/10.1007/s11695-013-1070-4

Kaye, W. H., Wierenga, C. E., Knatz, S., Liang, J., Boutelle, K., Hill, L., \& Eisler, I. (2015). Temperament-based treatment for anorexia nervosa. European Eating Disorders Review, 23(1), 12-18. https://doi.org/10.1002/erv.2330

Kolotkin, R. L., \& Andersen, J. R. (2017). A systematic review of reviews: exploring the relationship between obesity, weight loss and health-related quality of life. Clinical Obesity. https://doi.org/10.1111/cob.12203

Legenbauer, T., Petrak, F., de Zwaan, M., \& Herpertz, S. (2011). Influence of depressive and eating disorders on short- and long-term course of weight after surgical and nonsurgical weight loss treatment. Comprehensive Psychiatry, 52(3), 301-11. https://doi.org/10.1016/j.comppsych.2010.06.012

Livhits, M., Mercado, C., Yermilov, I., Parikh, J. a, Dutson, E., Mehran, A., ... Gibbons, M. M. (2012). Preoperative predictors of weight loss following bariatric surgery: systematic review. Obesity Surgery, 22(1), 70-89.

https://doi.org/10.1007/s11695-011-0472-4

Lo, Y., Mendell, N., \& Rubin, D. (2001). Testing the number of components in a normal mixture. Biometrika, 88, 767-778.

Maciejewski, M. L., Livingston, E. H., Smith, V. A., Kavee, A. L., Kahwati, L. C., 
Henderson, W. G., \& Arterburn, D. E. (2011). Survival Among High-Risk Patients After Bariatric Surgery. JAMA, 305(23), 2419. https://doi.org/10.1001/jama.2011.817

Maggard, M. A., Shugarman, L. R., Suttorp, M., Maglione, M., Sugerman, H. J., Sugarman, H. J., ... Shekelle, P. G. (2005). Meta-analysis: surgical treatment of obesity. Annals of Internal Medicine, 142(7), 547-59.

Magouliotis, D. E., Tasiopoulou, V. S., Svokos, A. A., Svokos, K. A., Sioka, E., \& Zacharoulis, D. (2017). One-Anastomosis Gastric Bypass Versus Sleeve Gastrectomy for Morbid Obesity: a Systematic Review and Meta-analysis. Obesity Surgery. https://doi.org/10.1007/s11695-017-2807-2

Malik, V. S., Willett, W. C., \& Hu, F. B. (2012). Global obesity: trends, risk factors and policy implications. Nature Reviews Endocrinology, 9(1), 13-27.

https://doi.org/10.1038/nrendo.2012.199

Manning, S., Pucci, A., Carter, N. C., Elkalaawy, M., Querci, G., Magno, S., ... Batterham, R. L. (2015). Early postoperative weight loss predicts maximal weight loss after sleeve gastrectomy and Roux-en-Y gastric bypass. Surgical Endoscopy, 29(6), 1484-91. https://doi.org/10.1007/s00464-014-3829-7

Montesi, L., El Ghoch, M., Brodosi, L., Calugi, S., Marchesini, G., \& Dalle Grave, R. (2016). Long-term weight loss maintenance for obesity: a multidisciplinary approach. Diabetes, Metabolic Syndrome and Obesity $\square$ : Targets and Therapy, 9, 37-46. https://doi.org/10.2147/DMSO.S89836

Mor, A., Sharp, L., Portenier, D., Sudan, R., \& Torquati, A. (2012). Weight loss at first 
postoperative visit predicts long-term outcome of Roux-en-Y gastric bypass using Duke weight loss surgery chart. Surgery for Obesity and Related Diseases $\quad \square$ : Official Journal of the American Society for Bariatric Surgery, 8(5), 556-60. https://doi.org/10.1016/j.soard.2012.06.014

Munro, I. A., Bore, M. R., Munro, D., \& Garg, M. L. (2011). Using personality as a predictor of diet induced weight loss and weight management. International

Journal of Behavioral Nutrition and Physical Activity, 8(1), 129.

https://doi.org/10.1186/1479-5868-8-129

Ng, M., Fleming, T., Robinson, M., Thomson, B., Graetz, N., Margono, C., ... Gakidou, E. (2014). Global, regional, and national prevalence of overweight and obesity in children and adults during 1980-2013: a systematic analysis for the Global Burden of Disease Study 2013. Lancet, 384(9945), 766-81. https://doi.org/10.1016/S01406736(14)60460-8

Niego, S. H., Kofman, M. D., Weiss, J. J., \& Geliebter, A. (2007). Binge eating in the bariatric surgery population: a review of the literature. The International Journal of Eating Disorders, 40(4), 349-59. https://doi.org/10.1002/eat.20376

NIH. (1992). Gastrointestinal surgery for severe obesity: National Institutes of Health Consensus Development Conference Statement. The American Journal of Clinical Nutrition, 55(2 Suppl), 615S-619S.

Nylund, K. L., Asparouhov, T., Muthén, M. \&, \& Muthén, B. O. (2007). Deciding on the Number of Classes in Latent Class Analysis and Growth Mixture Modeling: A Monte Carlo Simulation Study. Structural Equation Modeling, 14(4), 535-569.

This article is protected by copyright. All rights reserved. 
Obeidat, F., \& Shanti, H. (2015). Early Weight Loss as a Predictor of 2-Year Weight Loss and Resolution of Comorbidities After Sleeve Gastrectomy. Obesity Surgery, 26(6), 1173-1177. https://doi.org/10.1007/s11695-015-1903-4

Odom, J., Zalesin, K. C., Washington, T. L., Miller, W. W., Hakmeh, B., Zaremba, D. L., ... McCullough, P. A. (2010). Behavioral Predictors of Weight Regain after Bariatric Surgery. Obesity Surgery, 20(3), 349-356. https://doi.org/10.1007/s11695-009-9895-6

Pataky, Z., Carrard, I., \& Golay, A. (2011). Psychological factors and weight loss in bariatric surgery. Current Opinion in Gastroenterology, 27(2), 167-173. https://doi.org/10.1097/MOG.0b013e3283422482

Peterhänsel, C., Linde, K., Wagner, B., Dietrich, A., \& Kersting, A. (2017). Subtypes of Personality and "Locus of Control" in Bariatric Patients and their Effect on Weight Loss, Eating Disorder and Depressive Symptoms, and Quality of Life. European Eating Disorders Review, 25(5), 397-405. https://doi.org/10.1002/erv.2534 Rotella, F., Lazzeretti, L., Barbaro, V., Castellini, G., Bigiarini, M., Cresci, B., ... Mannucci, E. (2014). All roads bring to Rome: a different way for predicting success in the therapy of obesity through psychological features. Journal of Endocrinological Investigation, 37(12), 1187-94. https://doi.org/10.1007/s40618014-0130-5

Smith, S., \& Madden, A. M. (2016). Body composition and functional assessment of nutritional status in adults: a narrative review of imaging, impedance, strength and functional techniques. Journal of Human Nutrition and Dietetics, 29(6), 714-732. 
https://doi.org/10.1111/jhn.12372

Sullivan, S., Cloninger, C. R., Przybeck, T. R., \& Klein, S. (2006). Personality

characteristics in obesity and relationship with successful weight loss.

International Journal of Obesity, 31(4), 669-74.

https://doi.org/10.1038/sj.ijo.0803464

Swinburn, B. A., Sacks, G., Hall, K. D., McPherson, K., Finegood, D. T., Moodie, M.

L., \& Gortmaker, S. L. (2011). The global obesity pandemic: shaped by global drivers and local environments. The Lancet, 378(9793), 804-814.

https://doi.org/10.1016/S0140-6736(11)60813-1

Wadden, T. A., Faulconbridge, L. F., Jones-Corneille, L. R., Sarwer, D. B., Fabricatore, A. N., Thomas, J. G., ... Williams, N. N. (2011). Binge eating disorder and the outcome of bariatric surgery at one year: a prospective, observational study. Obesity, 19(6), 1220-8. https://doi.org/10.1038/oby.2010.336

Wimmelmann, C. L., Dela, F., \& Mortensen, E. L. (2014a). Psychological predictors of mental health and health-related quality of life after bariatric surgery: A review of the recent research. Obesity Research \& Clinical Practice, 8(4), e314-e324. https://doi.org/10.1016/j.orcp.2013.11.002

Wimmelmann, C. L., Dela, F., \& Mortensen, E. L. (2014b). Psychological predictors of weight loss after bariatric surgery: A review of the recent research. Obesity

Research \& Clinical Practice, 8(4), e299-e313.

https://doi.org/10.1016/j.orcp.2013.09.003

This article is protected by copyright. All rights reserved. 
Table 1. Sociodemographic comparison between trajectories

BMI Trajectories after BS

\begin{tabular}{|c|c|c|c|c|c|c|c|c|c|c|c|c|c|c|c|c|c|c|c|c|c|}
\hline \multirow{3}{*}{$=$} & \multirow{3}{*}{$\frac{(1)}{5}$} & \multirow{2}{*}{\multicolumn{2}{|c|}{$\begin{array}{l}\mathrm{T} 1 ; n=19 \\
\text { Good-fast }\end{array}$}} & \multirow{2}{*}{\multicolumn{2}{|c|}{$\begin{array}{c}\text { T2; } n=46 \\
\text { Good }\end{array}$}} & \multirow{2}{*}{\multicolumn{2}{|c|}{$\begin{array}{c}\text { T3; } n=31 \\
\text { Low }\end{array}$}} & \multirow{2}{*}{\multicolumn{2}{|c|}{$\begin{array}{l}\text { T4; } n=19 \\
\text { Low-slow }\end{array}$}} & \multicolumn{12}{|c|}{ Pairwise comparisons } \\
\hline & & & & & & & & & & \multicolumn{2}{|c|}{ T1vsT2 } & \multicolumn{2}{|c|}{ T1vsT3 } & \multicolumn{2}{|c|}{ T1vsT4 } & \multicolumn{2}{|c|}{ T2vsT3 } & \multicolumn{2}{|c|}{ T2vsT4 } & \multicolumn{2}{|c|}{ T3vsT4 } \\
\hline & & $\mathrm{n}$ & $\%$ & $\mathrm{n}$ & $\%$ & $\mathrm{n}$ & $\%$ & $\mathrm{n}$ & $\%$ & $p$ & $|d|$ & $p$ & $|d|$ & $p$ & $|d|$ & $p$ & $|d|$ & $p$ & $|d|$ & $p$ & $|d|$ \\
\hline \multirow[t]{2}{*}{ Sex } & Women & 13 & $68.4 \%$ & 36 & $78.3 \%$ & 22 & $71.0 \%$ & 14 & $73.7 \%$ & .402 & 0.22 & .849 & 0.06 & .721 & 0.12 & .467 & 0.17 & .690 & 0.11 & .836 & 0.06 \\
\hline & Men & 6 & $31.6 \%$ & 10 & $21.7 \%$ & 9 & $29.0 \%$ & 5 & $26.3 \%$ & & 0.22 & & 0.06 & & 0.12 & & 0.17 & & 0.11 & & 0.06 \\
\hline \multirow{2}{*}{ Civil status } & Married-partner & 9 & $47.4 \%$ & 28 & $60.9 \%$ & 19 & $61.3 \%$ & 7 & $36.8 \%$ & & 0.27 & & 0.28 & & 0.21 & & 0.01 & & 0.50 & & $0.50^{\top}$ \\
\hline & Separated-divorce & 1 & $5.3 \%$ & 3 & $6.5 \%$ & 1 & $3.2 \%$ & 2 & $10.5 \%$ & & 0.05 & & 0.10 & & 0.20 & & 0.15 & & 0.14 & & 0.29 \\
\hline \multirow[t]{2}{*}{ Employment statu } & us Unemployed & 8 & $42.1 \%$ & 20 & $43.5 \%$ & 10 & $32.3 \%$ & 11 & $57.9 \%$ & .919 & 0.03 & .481 & 0.20 & .330 & 0.32 & .322 & 0.23 & .290 & 0.29 & .075 & $0.53^{\dagger}$ \\
\hline & Employed & 11 & $57.9 \%$ & 26 & $56.5 \%$ & 21 & $67.7 \%$ & 8 & $42.1 \%$ & & & & & & & & & & & & \\
\hline Age (years-old); $m$ & mean-SD & 37.7 & 8.3 & 40.9 & 8.8 & 43.2 & 11.3 & 41.9 & 12.7 & .260 & 0.37 & .066 & 0.45 & .209 & 0.39 & .320 & 0.23 & .712 & 0.09 & .654 & 0.11 \\
\hline
\end{tabular}

Note. SD: standard deviation. *Significant comparison $\left(.05\right.$ level). ${ }^{\dagger}$ Bold: effect size in the moderate $(|d|>0.50)$ to good range $(|d|>0.80)$.

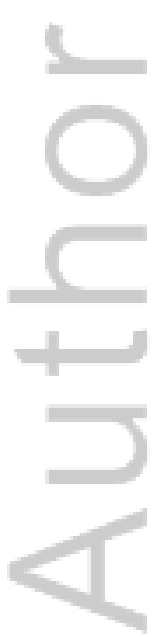

This article is protected by copyright. All rights reserved. 
Table 2. Comparison between trajectories in bariatric surgery subtype and metabolic state at baseline (prior to BS)

\begin{tabular}{|c|c|c|c|c|c|c|c|c|c|c|c|c|c|c|c|c|c|c|c|c|}
\hline \multirow{3}{*}{$=$} & \multirow{2}{*}{\multicolumn{2}{|c|}{$\begin{array}{l}\mathrm{T} 1 ; n=19 \\
\text { Good-fast }\end{array}$}} & \multirow{2}{*}{\multicolumn{2}{|c|}{$\begin{array}{c}\mathrm{T} 2 ; n=46 \\
\text { Good }\end{array}$}} & \multirow{2}{*}{\multicolumn{2}{|c|}{$\begin{array}{c}\text { T3; } n=31 \\
\text { Low }\end{array}$}} & \multirow{2}{*}{\multicolumn{2}{|c|}{$\begin{array}{l}\text { T4; } n=19 \\
\text { Low-slow }\end{array}$}} & \multicolumn{12}{|c|}{ Pairwise comparisons } \\
\hline & & & & & & & & & \multicolumn{2}{|c|}{ T1vsT2 } & \multicolumn{2}{|c|}{ T1vsT3 } & \multicolumn{2}{|c|}{ T1vsT4 } & \multicolumn{2}{|c|}{ T2vsT3 } & \multicolumn{2}{|c|}{ T2vsT4 } & \multicolumn{2}{|c|}{ T3vsT4 } \\
\hline & $\mathrm{n}$ & $\%$ & $\mathrm{n}$ & $\%$ & $\mathrm{n}$ & $\%$ & $\mathrm{n}$ & $\%$ & $p$ & $|d|$ & $p$ & $|d|$ & $p$ & $|d|$ & $p$ & $|d|$ & $p$ & $|d|$ & $p$ & $|d|$ \\
\hline Gastric bypass & 7 & $36.8 \%$ & 21 & $45.7 \%$ & 9 & $29.0 \%$ & 2 & $10.5 \%$ & .887 & 0.18 & .475 & 0.17 & .113 & $0.65^{\top}$ & .196 & 0.35 & $.013^{*}$ & $0.85^{\top}$ & .219 & $0.51^{\top}$ \\
\hline Duodenal switch & 2 & $10.5 \%$ & 5 & $10.9 \%$ & 9 & $29.0 \%$ & 6 & $31.6 \%$ & & 0.01 & & 0.48 & & $0.53^{\top}$ & & 0.47 & & $0.52^{\top}$ & & 0.06 \\
\hline Vertical sleeve gastrectomy & 9 & $47.4 \%$ & 17 & $37.0 \%$ & 11 & $35.5 \%$ & 11 & $57.9 \%$ & & 0.21 & & 0.24 & & 0.21 & & 0.03 & & 0.43 & & 0.46 \\
\hline Laparoscopic gastric plication & 1 & $5.3 \%$ & 3 & $6.5 \%$ & 2 & $6.5 \%$ & 0 & $0.0 \%$ & & 0.05 & & 0.05 & & 0.33 & & 0.00 & & 0.37 & & 0.37 \\
\hline Indicated BS-type Gastric bypass & 13 & $68.4 \%$ & 29 & $63.0 \%$ & 14 & $45.2 \%$ & 1 & $5.3 \%$ & .088 & 0.11 & .475 & $0.53^{\top}$ & .113 & $1.73^{\top}$ & .082 & 0.36 & $<.001^{*}$ & $1.54^{\top}$ & $.011^{*}$ & $1.03^{\top}$ \\
\hline Duodenal switch & 2 & $10.5 \%$ & 14 & $30.4 \%$ & 16 & $51.6 \%$ & 14 & $73.7 \%$ & & 0.48 & & $0.99^{\top}$ & & $1.66^{\top}$ & & 0.44 & & $0.96^{\top}$ & & 0.47 \\
\hline Vertical sleeve gastrectomy & 0 & $0.0 \%$ & 0 & $0.0 \%$ & 1 & $3.2 \%$ & 3 & $15.8 \%$ & & --- & & 0.26 & & $0.61^{\dagger}$ & & 0.26 & & $0.61^{\dagger}$ & & 0.44 \\
\hline Type-2 diabetes mellitus Present & 4 & $21.1 \%$ & 10 & $21.7 \%$ & 8 & $25.8 \%$ & 5 & $26.3 \%$ & .951 & 0.02 & .702 & 0.11 & .703 & 0.12 & .679 & 0.10 & .690 & 0.11 & .968 & 0.01 \\
\hline Arterial hypertension $\quad$ Present & 4 & $21.1 \%$ & 21 & $45.7 \%$ & 16 & $51.6 \%$ & 4 & $21.1 \%$ & .064 & $0.54^{\dagger}$ & $.032^{*}$ & $0.67^{\dagger}$ & .998 & 0.00 & .608 & 0.12 & .064 & $0.54^{\dagger}$ & $.032^{*}$ & $0.67^{\dagger}$ \\
\hline Dyslipidemia & 3 & $15.8 \%$ & 11 & $23.9 \%$ & 5 & $16.1 \%$ & 3 & $15.8 \%$ & .469 & 0.20 & .975 & 0.01 & .998 & 0.00 & .409 & 0.20 & .469 & 0.20 & .975 & 0.01 \\
\hline Apnea-obstruc. syndrome Present & 4 & $21.1 \%$ & 19 & $41.3 \%$ & 17 & $54.8 \%$ & 8 & $42.1 \%$ & .120 & 0.45 & $.019 *$ & $0.74^{\top}$ & .163 & 0.46 & .243 & 0.27 & .952 & 0.02 & .382 & 0.26 \\
\hline
\end{tabular}

Note. SD: standard deviation. BS: bariatric surgery *Significant comparison (.05 level). ${ }^{\dagger}$ Bold: effect size in the moderate $(|d|>0.50)$ to good range $(|d|>0.80)$.

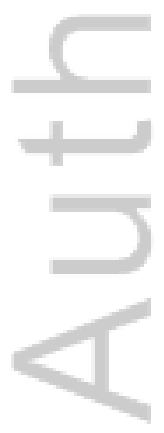

This article is protected by copyright. All rights reserved. 


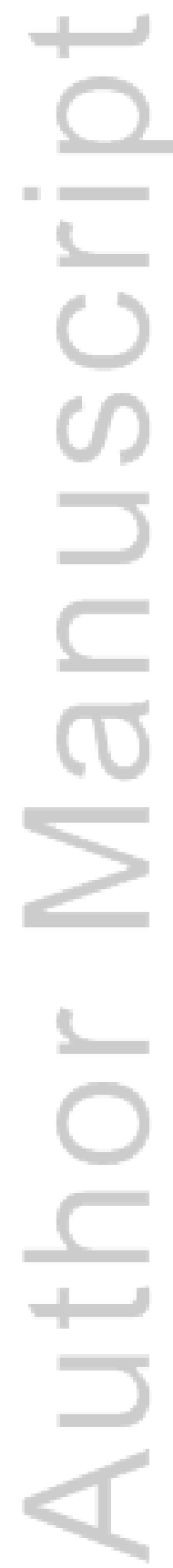

This article is protected by copyright. All rights reserved. 
BMI Trajectories after BS

Table 3. Comparison in psychological variables at baseline: results obtained via ANOVA procedures adjusted for BS-subtype and baseline metabolic state

\begin{tabular}{|c|c|c|c|c|c|c|c|c|c|c|c|c|c|c|c|c|c|c|c|c|}
\hline \multirow[b]{3}{*}{$=$} & \multirow{2}{*}{\multicolumn{2}{|c|}{$\begin{array}{l}\text { T1; } n=19 \\
\text { Good-fast }\end{array}$}} & \multirow{2}{*}{\multicolumn{2}{|c|}{$\begin{array}{l}\text { T2; } n=46 \\
\text { Good }\end{array}$}} & \multirow{2}{*}{\multicolumn{2}{|c|}{$\begin{array}{c}\text { T3; } n=31 \\
\text { Low }\end{array}$}} & \multirow{2}{*}{\multicolumn{2}{|c|}{$\begin{array}{l}\text { T4; } n=19 \\
\text { Low-slow }\end{array}$}} & \multirow{2}{*}{\multicolumn{2}{|c|}{ T1vsT2 }} & \multirow{2}{*}{\multicolumn{2}{|c|}{ T1vsT3 }} & \multicolumn{4}{|c|}{ Pairwise comparisons } & \multirow{2}{*}{\multicolumn{2}{|c|}{ T2vsT4 }} & \multirow{2}{*}{\multicolumn{2}{|c|}{ T3vsT4 }} \\
\hline & & & & & & & & & & & & & \multicolumn{2}{|c|}{ T1vsT4 } & \multicolumn{2}{|c|}{ T2vsT3 } & & & & \\
\hline & Mean & $S D$ & Mean & $S D$ & Mean & $S D$ & Mean & $S D$ & $p$ & $|d|$ & $p$ & $|d|$ & $p$ & $|d|$ & $p$ & $|d|$ & $p$ & $|d|$ & \multicolumn{2}{|c|}{$p \quad|d|$} \\
\hline SCL-90: Somatization & 1.18 & 0.96 & 1.11 & 0.73 & 1.24 & 0.93 & 1.45 & 0.90 & .794 & 0.07 & .804 & 0.07 & .343 & 0.29 & .534 & 0.15 & .185 & 0.41 & .426 & 0.23 \\
\hline SCL-90: Obsessive/compulsive & 1.10 & 0.97 & 0.85 & 0.63 & 1.05 & 0.78 & 1.08 & 0.59 & .213 & 0.31 & .831 & 0.05 & .958 & 0.02 & .235 & 0.29 & .260 & 0.39 & .876 & 0.05 \\
\hline SCL-90: Interpersonal sensitivity & 1.09 & 1.17 & 83 & 0.67 & 0.94 & 0.86 & 1.03 & 0.70 & .243 & 0.27 & .525 & 0.15 & .832 & .06 & .575 & .14 & .382 & 0.30 & .686 & 0.13 \\
\hline SCL-90: Depressive & 1.11 & 1.16 & 0.92 & 0.71 & 1.08 & 0.90 & 1.22 & 0.80 & .430 & 0.19 & .925 & 0.02 & .675 & 0.12 & .421 & 0.20 & .220 & 0.40 & .578 & 0.17 \\
\hline SCL-90: Anxiety & 0.82 & 1.02 & 0.65 & 0.55 & 0.85 & 0.75 & 0.74 & 0.55 & .368 & 0.21 & .904 & 0.03 & .723 & 0.10 & .229 & 0.30 & .648 & 0.17 & .610 & 0.16 \\
\hline SCL-90: Hostility & 0.62 & 0.97 & 0.41 & 0.40 & 0.54 & 0.61 & 0.71 & 0.81 & .256 & 0.28 & .697 & 0.09 & .700 & 0.09 & .402 & 0.25 & .129 & $0.50^{\top}$ & .416 & 0.22 \\
\hline SCL-90: P & 0.45 & 0.61 & 0.30 & 0.53 & 0.50 & 0.71 & 0.66 & 1.05 & .450 & 0.25 & .814 & 0.07 & .344 & 0.25 & .238 & 0.31 & .074 & 0.4 & .420 & 0.19 \\
\hline SCL-90: Paranoid Ideation & 0.95 & 1.07 & 0.59 & 0.47 & 0.77 & 0.70 & 0.88 & 0.69 & .053 & 0.44 & .367 & 0.20 & .739 & 0.08 & .257 & 0.30 & .140 & $0.50^{\top}$ & .590 & 0.16 \\
\hline : Psychotic & 0.58 & 0.90 & 0.35 & 0.36 & 0.52 & 0.58 & 0.68 & 0.58 & .141 & 0.34 & .728 & 0.08 & .614 & 0.12 & .199 & 0.36 & $.049 *$ & 0.6 & .367 & 0.26 \\
\hline il score & 0.93 & 0.93 & 0.72 & 0.49 & 0.88 & 0.68 & 1.01 & 0.60 & .232 & 0.28 & .780 & 0.07 & .705 & 0.10 & .296 & 0.26 & .118 & & .487 & 0.21 \\
\hline T score & 38.47 & 27.09 & 37.17 & 20.24 & 40.29 & 22.44 & 43.48 & 19.25 & .831 & 0.05 & .783 & 0.07 & .491 & 0.21 & .549 & 0.15 & .325 & 0.32 & .630 & 0.15 \\
\hline SCL-90: PSDI score & 1.89 & 0.72 & 1.65 & 0.51 & 1.82 & 0.59 & 1.99 & 0.58 & .123 & 0.38 & .675 & 0.11 & .567 & 0.16 & .202 & 0.30 & $.035^{*}$ & $0.63^{\dagger}$ & .294 & 0.30 \\
\hline thinness & 9.01 & 6.10 & 9.86 & 5.34 & 10.95 & 4.68 & 9.56 & 5.01 & .561 & 0.15 & .227 & 0.36 & .753 & 0.1 & .389 & 0.22 & .845 & 0.06 & .385 & 0.29 \\
\hline EDI: Body dissatisfaction & 15.34 & 7.40 & 16.75 & 7.34 & 17.84 & 6.33 & 18.53 & 6.01 & .470 & 0.19 & .240 & 0.36 & .173 & $0.51^{\top}$ & .512 & 0.16 & .386 & 0.27 & .747 & 0.11 \\
\hline oceptive awareness & 5.37 & 6.99 & 3.46 & 3.83 & 4.11 & 4.31 & 5.32 & 6.08 & .169 & 0.34 & .403 & 0.22 & .972 & 0.01 & .583 & 0.16 & .203 & 0.36 & .423 & 0.23 \\
\hline EDI: B & 3.06 & 5.10 & 1.11 & 1.52 & 1.37 & 1.59 & 3.12 & 4.67 & $.022^{*}$ & $\mathbf{0 . 5 2 ^ { \top }}$ & .068 & 0.45 & .953 & 0.01 & .710 & 0.17 & $.025^{*}$ & $0.58^{\top}$ & $.050 *$ & $\mathbf{0 . 5 2 ^ { \top }}$ \\
\hline ersonal distrust & 3.56 & 3.79 & 3.39 & 3.82 & 4.27 & 3.71 & 4.53 & 4.15 & .870 & 0.05 & .545 & 0.19 & .446 & 0.24 & .336 & 0.23 & .307 & 0.29 & .817 & 0.07 \\
\hline veness & 5.03 & 7.31 & 3.47 & 3.57 & 5.03 & 4.17 & 4.63 & 4.92 & .235 & 0.2 & .997 & 0.00 & .801 & 0.06 & .163 & 0.40 & .397 & 0.27 & .778 & 0.09 \\
\hline EDI: & 6.20 & 3.58 & 4.84 & 3.23 & 6.95 & 4.35 & 6.62 & 4.45 & .202 & 0.40 & .515 & 0.19 & .740 & 0.10 & $.021 *$ & $0.55^{\dagger}$ & .112 & $0.50^{\dagger}$ & .773 & 0.0 \\
\hline onism & 3.39 & 3.11 & 3.25 & 2.87 & 1.92 & 2.05 & 2.80 & 2.94 & .851 & 0.05 & .072 & $0.56^{\dagger}$ & .501 & & $.039 *$ & $0.53^{\dagger}$ & .557 & & .283 & 0.34 \\
\hline se regulation & 1.35 & 3.19 & 1.54 & 2.20 & 2.24 & 3.34 & 3.07 & 3.85 & .828 & 0.07 & .344 & 0.27 & .096 & $0.51^{\top}$ & .342 & 0.25 & .091 & $0.55^{\top}$ & .372 & 0.23 \\
\hline EDI: A & 4.66 & 3.68 & 4.12 & 3.36 & 5.37 & 3.51 & 5.55 & 2.76 & .569 & 0.16 & .498 & 0.20 & .442 & 0.27 & .128 & 0.37 & .158 & 0.47 & .868 & 0.05 \\
\hline EDI: $S$ & 4.27 & 5.67 & 2.69 & 2.93 & 3.50 & 3.25 & 3.72 & 3.62 & .128 & 0.35 & .493 & 0.17 & .657 & 0.12 & .361 & 0.26 & .342 & 0.31 & .842 & 0.07 \\
\hline EDI: Total score & 61.26 & 38.88 & 54.48 & 25.48 & 63.57 & 23.72 & 67.50 & 29.51 & .388 & 0.21 & .787 & 0.07 & .506 & 0.18 & .177 & 0.3 & .116 & $0.53^{\top}$ & .644 & 0.15 \\
\hline TCI-R: Novelty seeking & 92.82 & 10.58 & 96.03 & 12.32 & 96.66 & 13.59 & 99.40 & 17.16 & .378 & 0.28 & .333 & 0.32 & .132 & $0.50^{\top}$ & .840 & 0.0 & .380 & 0.23 & .490 & 0.18 \\
\hline TCI-R: Harm avoidance & 104.21 & 23.18 & 104.44 & 14.53 & 103.79 & 19.29 & 106.90 & 15.67 & .962 & 0.01 & .938 & 0.02 & .642 & 0.14 & .876 & 0.04 & .630 & 0.16 & .556 & 0.18 \\
\hline TCI-R: Reward dependence & 111.05 & 14.44 & 109.59 & 13.40 & 108.27 & 16.11 & 107.81 & 13.35 & .718 & 0.10 & .528 & 0.18 & .501 & 0.23 & .702 & 0.09 & .673 & 0.13 & .915 & 0.03 \\
\hline TCI-R: Persistence & 114.78 & 25.01 & 108.19 & 17.19 & 111.47 & 14.21 & 103.15 & 16.60 & .193 & 0.31 & .547 & 0.16 & $.048 *$ & $0.55^{\dagger}$ & .446 & 0.21 & .343 & 0.30 & .130 & $0.54^{\dagger}$ \\
\hline
\end{tabular}

This article is protected by copyright. All rights reserved. 
BMI Trajectories after BS

TCI-R: Self-directedness TCl-R: Cooperativeness

\begin{tabular}{ll|ll|ll|ll|}
144.99 & 28.59 & 143.25 & 20.51 & 141.04 & 25.20 & 137.71 & 17.02
\end{tabular}

TCl-R: Self-Transcendence

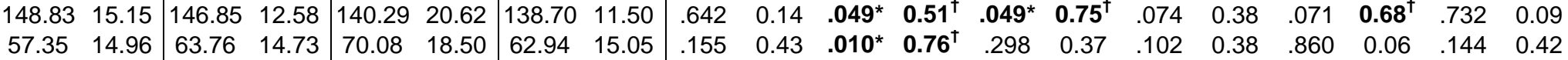

Note. SD: standard deviation. *Significant comparison (.05 level). ${ }^{\dagger}$ Bold: effect size in the moderate $(|d|>0.50)$ to good range $(|d|>0.80)$.

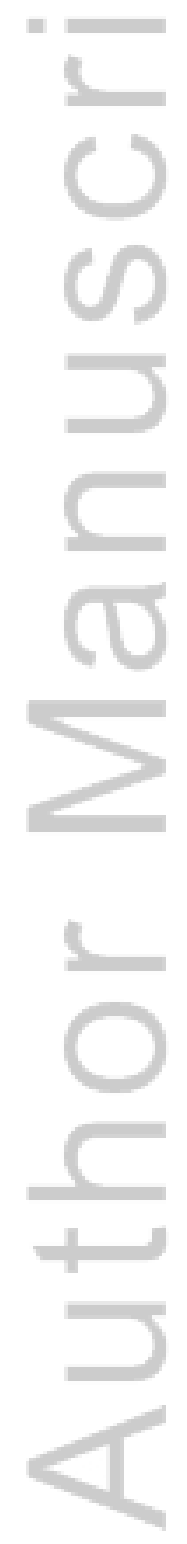

This article is protected by copyright. All rights reserved. 
Figure 1. Body mass index trajectories: from pre-surgery to 12-months following bariatric surgery

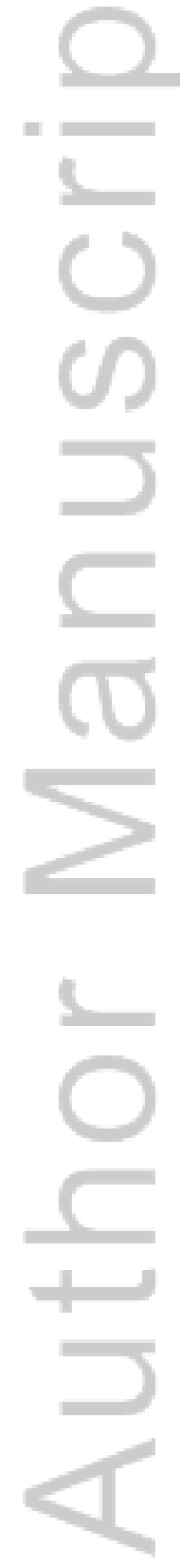

This article is protected by copyright. All rights reserved. 
Figure 2. Radar-chart with the main variables differing between the empirical trajectories

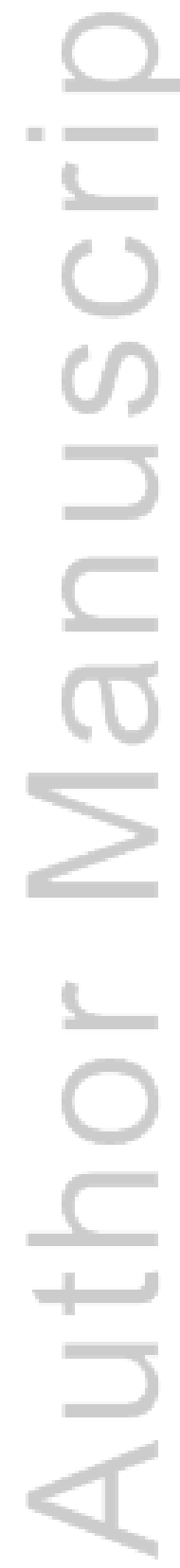

This article is protected by copyright. All rights reserved. 


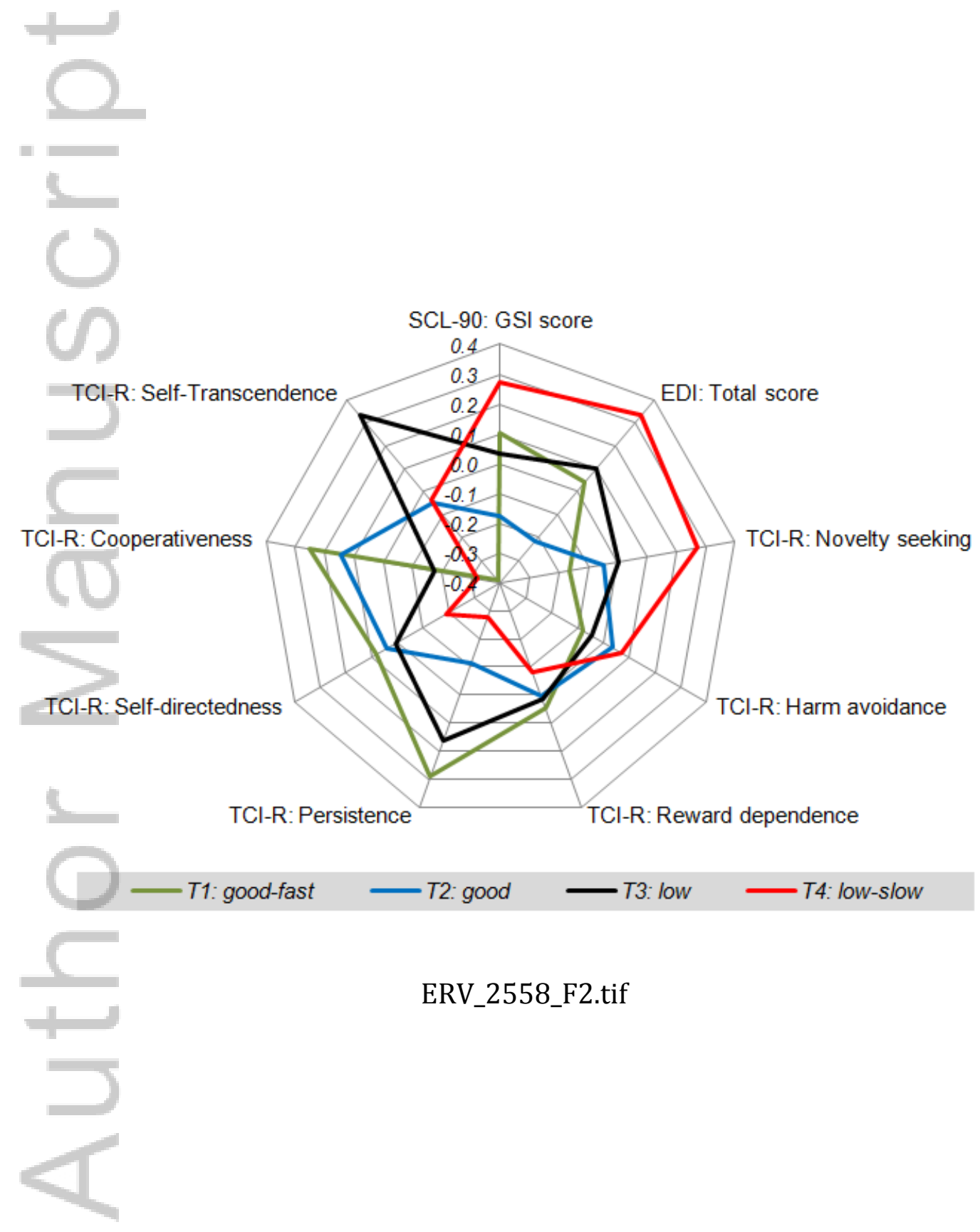

This article is protected by copyright. All rights reserved. 


\section{University Library}

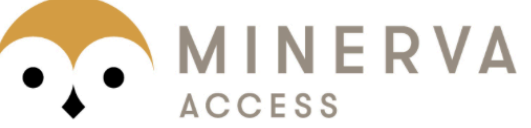

A gateway to Melbourne's research publications

Minerva Access is the Institutional Repository of The University of Melbourne

\section{Author/s:}

Garcia-Ruiz-de-Gordejuela, A;Aguera, Z;Granero, R;Steward, T;Llerda-Barbera, A;LopezSegura, E;Vilarrasa, N;Sanchez, I;Jimenez-Murcia, S;Virgili, N;Lopez-Urdiales, R;de Bernabe, MM-G;Garrido, P;Monseny, R;Monasterio, C;Salord, N;Pujol-Gebelli, J;Menchon, JM;Fernandez-Aranda, F

Title:

Weight Loss Trajectories in Bariatric Surgery Patients and Psychopathological Correlates

Date:

2017-11-01

\section{Citation:}

Garcia-Ruiz-de-Gordejuela, A., Aguera, Z., Granero, R., Steward, T., Llerda-Barbera, A., Lopez-Segura, E., Vilarrasa, N., Sanchez, I., Jimenez-Murcia, S., Virgili, N., LopezUrdiales, R., de Bernabe, M. M. -G., Garrido, P., Monseny, R., Monasterio, C., Salord, N., Pujol-Gebelli, J., Menchon, J. M. \& Fernandez-Aranda, F. (2017). Weight Loss Trajectories in Bariatric Surgery Patients and Psychopathological Correlates. EUROPEAN EATING DISORDERS REVIEW, 25 (6), pp.586-594. https://doi.org/10.1002/erv.2558.

Persistent Link:

http://hdl.handle.net/11343/293540 